\title{
Clima organizacional y satisfacción laboral de los colaboradores del área asistencial de un Hospital II- E de San Martín
}

\author{
Mtro. Juan Carlos Ulises Arévalo Barrera \\ jucar021179@gmail.com \\ ORCID: 0000-0002-3052-5559 \\ Mtra. Sonia Janett Quiroz Carhuatanta \\ sonquiroz@unsm.edu.pe \\ ORCID: 0000-0002-5278-1297
}

Dr. José Manuel Delgado Bardales

jmdelgadob@ucvvirtual.edu.pe

ORCID: 0000-0001-6574-2759

Universidad César Vallejo

\section{RESUMEN}

La investigación titulada "Clima organizacional y satisfacción laboral de los colaboradores del área asistencial del Hospital II-E Banda de Shilcayo, 2018”, tuvo como objetivo determinar la relación entre el clima organizacional y la satisfacción laboral de los colaboradores del Área Asistencial del Hospital II-E Banda de Shilcayo, 2018. La muestra estuvo conformada por 119 colaboradores del Hospital II-E Banda de Shilcayo. La investigación fue de tipo básica descriptiva y no experimental, de diseño descriptivo correlacional. Para la recolección de información se utilizó la técnica de encuesta y como instrumento dos cuestionarios uno para clima organizacional y el otro para satisfacción laboral. Resultados, los colaboradores asistenciales del Hospital II-E Banda de Shilcayo, perciben un clima organizacional medio con 50,4\%, seguido del 37,0\% que lo califica como “desfavorable". Según dimensiones, el 41,2\% de los colaboradores refieren que el clima organizacional en la dimensión realización personal es desfavorable; el 45,4\% refiere que en la dimensión involucramiento personal, supervisión y el clima organizacional es media respectivamente. La satisfacción laboral que presenta el colaborador asistencial del Hospital II-E Banda de Shilcayo, es "mediana satisfacción laboral" con 49,6\% y el 33,6\% lo califica en baja satisfacción laboral. En conclusión, existe una correlación positiva moderada entre las variables clima organizacional y satisfacción laboral coeficiente de correlación de Pearson $(0,460)$. Además, existe 
asociación lineal fundamento de correlación de Pearson, el coeficiente de determinación $(0,2113)$ nos explica que la satisfacción laboral de los colaboradores asistenciales se ve influenciado por el clima organizacional.

Palabras claves: clima organizacional; satisfacción laboral; área asistencial. 


\title{
Organizational climate and job satisfaction of the collaborators in the healthcare area of an II-E Hospital in San Martín
}

\begin{abstract}
The research work entitled "Organizational climate and job satisfaction of the collaborators of the Banda de Shilcayo Hospital II-E, 2018", aimed to determine the relationship between the organizational climate and job satisfaction of the collaborators of the Banda Shilcayo Hospital II-E, 2018. Likewise, the sample consisted of 119 employees of the Micro network Banda de Shilcayo. The investigation was of a descriptive and non-experimental basic type, with a correlational descriptive design. For the collection of information, the survey technique was used and, as an instrument, two questionnaires were used, one for organizational climate and the other for job satisfaction. Results, the healthcare collaborators of the Banda de Shilcayo Hospital II-E, perceive an average organizational climate with $50.4 \%$, followed by $37.0 \%$ that qualifies it as "unfavorable". According to dimensions, $41.2 \%$ of the collaborators say that the organizational climate in the dimension of personal fulfillment is unfavorable; $45.4 \%$ said that in the dimension of personal involvement, supervision and the organizational climate is average, respectively. The occupational satisfaction that the collaborator of the Banda de Shilcayo Hospital II-E presents, is "average job satisfaction" with $49.6 \%$ and $33.6 \%$ qualifies it as low job satisfaction. In conclusion there is a moderate positive correlation between the variable's organizational climate and job satisfaction Pearson correlation coefficient (0.460). In addition, there is a linear association based on the Pearson correlation, the coefficient of determination (0.2113) explains that the job satisfaction of the assistances collaborators is influenced by the organizational climate.
\end{abstract}

Keywords: Organizational climate, job satisfaction, healthcare area

Artículo recibido: 02 Setiembre. 2021 Aceptado para publicación: 30 Setiembre. 2021 Correspondencia: jucar021179@gmail.com Conflictos de Interés: Ninguna que declarar 


\section{INTRODUCCIÓN}

Se comprende al clima organizacional como la percepción de los integrantes de la organización en referencia al trabajo, también es referido al espacio físico en donde ocurre los hechos en las competencias entre compañeros que se suscitan en referencia al de las demás relaciones formales e informales que ejecutan las labores (Cabrera, 1996, p.27). El estudio y el análisis sobre el tema de clima laboral es primordial y fundamental para la mejora continua de las empresas, porque es un indicador muy preciso la cual nos confirma los grados que se tiene en cualquier empresa en referencia a las correlaciones laborales. Por ello con un excelente clima laboral se puede augurar un sin número de sucesos que se soltaran por medio de la certeza que se tenga, si es un indicador positivo se espera diversos beneficios para ambos actores (empleadores y empresa) pero si es negativa lo que podemos esperar es perdidas, conflictos internos y externos, gastos y otras situaciones desfavorables que llevan a la empresa a múltiples conflictos Ortiz y Cruz, 2008, p. 13). Entre las variables que se interrelaciona en forma vertical con lo del clima laboral es el completo bienestar y deleite laboral, en los análisis que se hace sobre el tema los jefes superiores son aquellos que tienen la facultad de obtener información muy significativa en referencia al efecto de las normas, las disposiciones generales que se hace, también sombre las políticas hospitalarias para así poder tomar las decisiones correctas y optimistas que en forma global lo más importante que se toman a los colaboradores asistenciales quienes son los principales protagonistas y si sienten el gusto o rechazo tanto por lo que la institución des da y cómo es que este actor permite la ejecución de mejor desempeño de las labores (Lozano, Santos y Arcubia, 2008, p. 12). Distintos estudios en referencia al clima organizacional se obtienen como predominio en el dialogo y las relaciones entre compañeros de trabajo, además de la responsabilidad que asume el empleado, su salud, su bioseguridad, también la motivación en su centro de labores (León, 2000, p. 26).

De acuerdo a lo establecido por la Organización Panamericana de la Salud, lo define al clima organizacional como un conjunto de percepciones donde las características son relativamente estables dentro de una organización el cual confluye todas las actividades además de las actividades y las actitudes que toman los miembros de la organización" (Marín, Melgar y Castaño, 2000, p. 15). En un estudio que se realizó en África, se demostró que la empresa podría ampliar el agrado por el trabajo por medio de un buen 
clima laboral, además otras investigaciones demuestran que un buen clima en la organización se correlaciona verticalmente con el mejor beneplácito en la empresa y no desean abandonar el trabajo (Borhani, 2012, p. 20). Un estudio en referencia al tema que se realizó en Centro América (México), se determinó que el 76\% de los empleados declararon la presencia de un excelente clima en el centro de trabajo, en referencia con la satisfacción en el trabajo se encontró que el $42 \%$ están regularmente satisfechos de su trabajo (Carballo, Romeo y Ávalos, 2015, p. 59). Durante un estudio se concluyó que si hay una excelente relación interpersonal crece el grado de satisfacción por el trabajo desarrollado además de considerarse como uno de los factor protector para un desgaste profesional, por lo que debe existir la motivación en los trabajadores, es así que en el en el ámbito hospitalario se aplica la teoría de Maslow, para comprender por qué existen problemas de motivación refiriéndose que el ser humano para su supervivencia a lo largo del tiempo se organiza en diferente niveles u con una jerarquía importancia (Avalos y Molina, 2009, p. 218-225).

En el estudio de Gallup (2013), encontró que el 87\% de los trabajadores sienten a trabajo como una fuente de frustración, pero el nivel de satisfacción es en un $90 \%$ a nivel global, determino que los grados más elevados de desconexión y que odian al trabajo que se halla en medio oriente y al norte de África, según este estudio los empleados felices en Siria es cero, en Argelia solo el 12\% es feliz, en Túnez es solo el 5\% de empleados. Sim embargo en Qatar hubo una mejor calificación con un $28 \%$ que es feliz con su trabajo, el $62 \%$ es mediamente satisfecho y solo un $10 \%$ de los trabajadores odia a su trabajo actual (Chiavenato, 2009).Actualmente, en España los profesionales están por arriba de la media Europea con un $75 \%$ con un cinco por ciento menos que los países Bajos con un $78 \%$, seguidamente de Alemania con 75\%, Bélgica con un 74\%, Portugal con 74\% y Francia con $72 \%$. Sin embargo, la tasa de satisfacción más elevada fueron Noruega con Austria los dos con 81\%. En América, Estados Unidos, sorprendentemente el 78\% están contentos con su puesto laboral actual (Gallup, 2013, p. 5).

En nuestro país siempre se tomó muy en serio el tema de Clima Organizacional, por lo que desde las altas esferas del Ministerio de salud (MINSA, es por ello que se promulgo la norma técnica (RM468/2011/MINSA), el cual tiene el compromiso se ser actualizada habitualmente y de manera progresiva todos los estándares y los lineamientos que son importantísimos para tener un excelente sistema de gestión de la calidad de salud, esto en 
conformidad con el desarrollo de nuestro país y de la sociedad (Randstad, 2015). Durante los últimos años, la salud ha ido mejorando gracias a la atención de salud con calidad, el cual se fue convirtiendo en un tema importante para las diversas unidades prestadoras de salud tanto públicas como privadas, ya que tiene una repercusión vertical sobre el estado de la salud de los usuarios y demás beneficiarios tanto económicos como administrativos. Es en ese sentido que se ha reconocido que para que haya una buena atención en salud y con calidad, uno de los pilares fundamentes y es más influyente es el recurso humano, quien dentro de un excelente clima laboral pueda estar satisfecho para hacer que la institución alcance tosas las metas propuestas en todos los aspectos. Las unidades prestadoras de salud son influenciadas directamente por múltiples factores que trasgreden en la eficacia de la misma, es por ello que los estilos de liderazgo de los gerentes y ejecutivos que no se quedan mucho tiempo en un cargo importante, también es importante mencionar la deficiencia de la comunicación entre el personal, además la rotación excesiva de los trabajadores de la parte asistencial y la parte administrativa sin aviso previo, el roce que se da entre los valores personales y el de la institución debilitan al personal, esto conllevara a un desinterés generalizado de los empleados y repercute en los ambientes laborales, por lo cual se desarrolla un feo clima en la organización, además de un clima tenso y sobre todo autoritario que disminuyen la capacidad de los empleados en sus quehaceres, que además generan un enorme falta de compromiso y el desinterés de todo el personal y que tiene relevancia en todos los miembros que la conforman en el servicio de salud (MINSA, 2015).

Monteza N, en la ciudad de Chiclayo (2010), con su tema de investigación titulado "Influencia del clima laboral en la satisfacción de las enfermeras en un centro quirúrgico" del hospital regional de EsSalud Chiclayo; llego a una conclusión que si existe una falta oportuna de comunicación con una cifra de $81.8 \%$ además se encontró que existe una mala orientación de los recursos humanos en el INO 57,3\% el cual es influenciado por el personal de la parte administrativa del sexo femenino y nombrado por lo tanto la suma de todos estos factores conllevan a determinar un clima organizacional inadecuado y hostil (p. 20). En la Institución "Liga Contra el Cáncer, Pueblo Libre”; con respecto al clima organizacional ante las percepción de las investigadoras durante la práctica laboral al interactuar con el personal profesional de la salud un $40 \%$ del personal de enfermería, obstetras y el personal técnico que labora manifiestan que, "a veces no siento esa 
motivación que me levante feliz para venir al trabajo", manifiestan también como "trabajo demasiadas horas", dicen también "hay demasiados pacientes", además "falta personal", entre otras expresiones, con respecto a satisfacción laboral ante la percepción de las investigadoras el 50\% de personal administrativo manifiesta "me siento bien pero no conforme con mi sueldo", "mayormente salgo a la hora indicada ", a veces en campañas hay mucha gente y falta personal; un $10 \%$ solo trabaja sin comentar y manifestar estas expresiones (Álvarez, 2001, p. 15). En general un 30\% no está conforme con su trabajo, que se puede evidenciar que existe insatisfacción laboral por el ausentismo, tardanzas, faltas sin previo aviso, rotación de personal para cubrir las ausencias, menor productividad y baja calidad de atención, estas actitudes y comportamiento se desenvuelven en un entorno tenso que de alguna u otra manera conlleva a tener un clima laboral y organizacional poco participativo (Arévalo y Tapia, 2016, p. 18).

A nivel nacional en las unidades prestadoras de salud y especialmente en los centros de salud que son dependientes del Ministerio de Salud (MINSA), los que trabajan son profesionales de la salud, además de técnicos administrativos, técnicos auxiliares y asistenciales que apoyan directamente todos los procesos administrativos que en cada institución se desarrolla con una sola finalidad de cumplir la política de disminuir los casos de enfermedades promoviendo las diversas estrategias de prevención y promoción universal (Robbins, 2004, p. 439). En tal sentido el desgate del clima organizacional dentro de las unidades prestadoras de salud comprende entonces un ítem negativo para la búsqueda de una excelente calidad en la prestación de salud en consecuencia afecta el compromiso que deben tener el personal que labora en la institución (Picoy, 2014, p. 25). Situaciones como lo mencionado existe también en el Hospital II-E Banda de Shilcayo, pues existe mucho descontento de parte del personal administrativo y asistencial debido a los estilos de liderazgo y ejercicio de jefaturas con gestión deficiente basado en el sentido amical y poco técnico, a esto se suma el exceso de funciones por la alta demanda de pacientes y el escaso personal asistencial; problemas que conllevan a la existencia de un clima laboral y organizacional deficiente. Es por eso que el trabajo de investigación pretende conocer con precisión el estudio del clima organizacional y el nivel de satisfacción de los colaboradores del área asistencial del Hospital II-E Banda de Shilcayo, para luego evaluar la correlación y así determinar si existe asociación significativa entre las dos variables. 
A nivel internacional, García Y. (2016), concluye que, en ambas instituciones están algo satisfechas de acuerdo a su nivel de satisfacción laboral, en referencia a la satisfacción extrínseca demuestran también que los trabajadores están algo satisfechos, pero en cambio en la motivación extrínseca la percepción es diferente. En relación a la satisfacción intrínseca se encontró que en los dos hospitales el factor que tiene más valoración es la satisfacción que le genera al tener un empleo con una calificación de satisfacción elevada, en cambio el factor que tiene menor calificación fue el del apoyo a alcanzar los objetivos y metas a lograr, en referencia a la satisfacción extrínseca, el componente que presentas un menor puntaje es el deleite por el sueldo que recibe. En conclusión, al relacionar la satisfacción laboral con los siete factores extrínsecos y los cuatro intrínsecos se halló una correlación positiva (p. 9). También Carballo A. (2015), concluye que, el $76 \%$ de los empleados dicen que, si existe un clima favorable, además la satisfacción laboral con un $46 \%$ muestra que está parcialmente satisfecho. El estudio concluye que: la apreciación de los trabajadores operativos en referencia al clima organizacional es favorable, pero la gran cantidad del personal operativo nos refiere estar en regular y parcial en su nivel de satisfacción personal, esto nos muestra que a futuro hay más probabilidad de desarrollar conflictos en la institución (12).

Agudelo, R. (2015), concluye que se obtuvo fue que el clima organizacional resulto con un promedio de 69.81 , además hubo una calificación de 3.89 lo cual lo catalogo como un nivel medio el clima organizacional con la dimensión de las relaciones entre compañeros de trabajo. En conclusión, existe una evidencia clara del valor que tiene el empleado partiendo desde la interacción amigable entre integrantes de la organización o desde el punto de vista de la interacción amigable, afectiva y respetuosa con los demás colaboradores del área de trabajo, vital para lo cual se debe tener un ambiente de labores de un equipo muy sólido. También se demostró que la relación interpersonal con la coordinación externa es importante que la tenga el trabajador ya que se le asigna una forma de liderazgo muy participativo en su percepción del clima organizacional (p. 20). Además, Carvajal, L. (2014), encontró que, de manera global los niveles de clima organizacional son muy variados, se encontró que la ayuda de su superior o jefe, la unidad de salud, el confort y la afinidad entre compañeros en donde el clima laboral es estable y optimo, sin embargo, la variable recompensa es bajo, pero la variable de control y presión su puntuación es alto (27). A nivel nacional, Vallejos, M. (2017), demuestra con certeza 
que hay una relación directa entre el clima organizacional y la satisfacción laboral en dicha Micro red de Salud San Martin en el año 2017 y lo confirma la prueba de coeficiente de correlaciona Rho de Spearman de 0,701 lo que significa una alta relación de variables (p. 28). Igualmente, Navarro, R. (2017), encontró que el 55.5\% tiene un nivel medio al clima organizacional y un $44.1 \%$ afirma que es alto el nivel del clima organizacional, se concluye en el estudio que existe un excelente clima laboral en esta institución, sin embargo un $44.9 \%$ tiene un nivel medio a la satisfacción laboral y un $55.1 \%$ de la población en estudio afirma que es alto la satisfacción laboral, se llega a la conclusión según el coeficiente Rho de Spearson existe una correlación significativa de 0,857 entre ambas variables (p. 31).

También, Arévalo, P. (2016), encontró que el 50.0\% afirma tener un clima laboral favorable, el 41.7 medio favorable y el $6.3 \%$ desfavorable, finalmente el $2.1 \%$ afirma tener un clima muy favorable. en referencia a la satisfacción laboral, el $85.4 \%$ se encuentran satisfechos, medianamente satisfecho con un $6.3 \%$ y los empleados muy satisfechos con el $6.3 \%$ y para finalizar la categoría insatisfecha con un $2.21 \%$. El estudio concluye que hay una relación directa entre las dos variables de estudio (clima organizacional) y (satisfacción laboral) y esto se demuestra mediante la prueba $\mathrm{r}$ Pearson= 0,574 valor p<0.001 (30). Igualmente, Rivera I. (2015), concluye que existe una relación entre el clima organizacional y la satisfacción laboral el arroja un 70\% propicio para la relación de ambas variables, en referencia al clima organizacional su obtuvo 168,73 de un total de 250 puntos, de igual forma los empleados satisfechos obtuvieron 112,67 de un total de 180 puntos; en tal sentido la prueba de Fisher arroja una diferencia significativa de $(p=0,012)$ lo cual indica que si hay relación de ambas variables del estudio (p. 9). Además, Huamán G. (2015), concluye que, el estudio demostró que si hubo relación entre las variables; es por ello que la prueba de hipótesis de coeficiente de correlación Spearman tuvo el valor de 0,274 y el valor $\mathrm{P}=0,030$ y fue un valor menor mayor a 0,025 es por ello que si acepta la hipótesis del estudio, es por ello que el 50,8\% de los empleados manifiesta tener un regular clima organizacional y además de tener una satisfacción laboral alta de 49,2\% lo que confirma que ambas variables se relacional verticalmente (p. 12).

A nivel regional y local, Panduro J. (2012), concluye que los trabajadores muestran que el clima organizacional es la dimensión con más frecuencia y se caracteriza por la práctica 
de relaciones humanas entre el personal y los usuarios en la atención de la salud. En la dimensión calidad persistió la claridad y la coherencia en la alta jerarquía quien dirige la institución a medida que las metas y los programas se cumplen a cabalidad se acuerdo a los criterios las políticas públicas. En conclusión, si existe una estrecha relación entre el clima organizacional y la calidad de la atención es en tal sentido que se obtuvo un X2 de 23,9 y el margen de error es de 0,05 con 14 grados de libertad y dando un X2 tabular de 23,68 (p. 10).

Entre las teorías relacionadas al Clima Organizacional, se define así al conjunto de percepciones que se comparten por un grupo de personas en una organización en relación al trabajo, las relaciones entre compañeros(as) de trabajo además de compartir el ambiente físico, además de las múltiples regulaciones informales y formales que dificultan dicho trabajo (MINSA, 2009). El clima laboral son aquellas características del lugar donde labora que son percibidas de una manera directa o indirecta por los integrantes de la organización dado que provoca diversos resultados de diferente tipo de comportamiento de acuerdo al grado de satisfacción de la tarea encomendada, se afirma que el clima organizacional es un componente principal que actúa directamente entre el sistema organizacional y en comportamiento del grupo la cual retroalimenta los procesos en la empresa (Alvarado, 2014, p. 38). Al clima organizacional también se lo cataloga como una percepción determinada de los integrantes de la institución, además de ser las actitudes, conductas y vivencias en la organización, es por ello que el clima va influenciar en el comportamiento de los seres humanos, además es una variable que interviene directamente en la estructura propia de la organización y la conducta, es por ello que se dice que de una u otra forma va influenciar directamente en el quehacer de los individuos (Noboa, 2007, p. 1).

En los sistemas de salud la cultura organizacional no es más que una mescla heterogénea de conductas, creencias, saberes, relatos, que todos comparten entre como, por ejemplo: las actitudes, los valores, las normas, el lenguaje, el estilo de vida, el dialogo y además de la terminología propia de la carrera de biomédicas y sociales (Carrada, 2002, p. 41). Chiavenato I. (2009), lo describe al clima organizacional como el lugar donde existe miembros de una organización que esta afín con el nivel de estimulación de los integrantes ya que se basa en los estados emotivos de los empleados el cual son el resultado de la forma como se desarrolla dentro de dicho ambiente laboral la cual se 
desarrolla mediante el dialogo, el liderazgo de los gerentes, las perspectivas de desarrollo y el reconocimiento de los salarios y las compensaciones (Chiavenato, 2009, p. 30). Según Goncalves A. (2000), considera que el clima laboral es un fenómeno laboral donde interactúan diversos elementos institución sumado a los nuevos estilos de motivación que se convierte en una conducta que conlleva a tener secuelas a la organización ya sea en la satisfacción, la rotación y la mayor productividad. Es por ello que para entender con más claridad el concepto de clima organizacional tenemos que tener en cuenta los siguientes conceptos: Se denomina clima a todas las particularidades en el entorno del trabajo. Estas particularidades son apreciadas indirecta o directa por los integrantes de la organización. El clima contiene secuelas del desempeño profesional.

El clima laboral es una variable que interactúa en forma media en el sistema organizacional. Existe algunas características que son relativas con el tiempo y son diversas entre si dentro de la misma empresa. Las estructuras, las diversas características, el clima y los integrantes son independientes y muy dinámicas. Para Brunet, L. (2011), el clima organizacional es como la distribución de los diversos tipos de organización, las características individuales propias que construyen la personalidad, es decir, que el comportamiento del empleado en su desempeño laboral será influido de acuerdo al clima organizacional que lo agrupa. El ambiente laboral dentro de la organización puede desintegrarse en elementos estructurales, el tipo de liderazgo, la comunicación y la dirección de procesos, etc. (p. 40). De algún modo posible, el temperamento de una empresa influirá en la conducta de sus trabajadores, esto se debe a las propias características que presenta el Clima Organizacional. Menciona que estas características son: (Taguiri, 1968, p. 1). El clima viene a ser la distribución específica de diversas variables ocasionales. Los elementos que lo componen pueden cambiar, pero el clima tiende a ser el mismo. El clima puede tener una "relación de secuencia" pero jamás de forma seguida, es por ello que cambia después de cualquier intervención. El clima puede ser determinado en varias partes por las características, actitudes y aptitudes, además de las conductas propias de una organización. El clima es totalmente exterior a la personal, es por ello que se siente como un elemento que puede contribuir al desarrollo del mismo. Su base principal del clima es las características de la situación externa y similar al del observador como con el actor. Puede tener secuelas directas sobre el comportamiento. 
El clima es un agente que determina de forma directa sobre el comportamiento individual y grupal porque procede de actitudes y muchas expectativas al comportamiento (Taguiri, 1968, p. 1). MINSA (2009), menciona que el clima organizacional son aquellas cataduras que tienen una estrecha correspondencia con el ambiente de la empresa en el cual interactúan todos sus integrantes. Y entre las características que la definen son: Tiene que tener vigencia, por sobre todas las cosas que pueda hacer permutas en muchas situaciones. Debe tener una señal vertical sobre el comportamiento de los integrantes de la institución. Tiene que afectar al nivel de trabajo de los integrantes de la institución. Puede ser afectado por todas las variables estructurales (p. 20). Importancia del clima organizacional. Según el Ministerio de Salud (MINSA), en su documento llamado "Metodología para el estudio del clima organizacional" es cual lo describe y lo estudia al clima organizacional de una forma más precisa, sistemática y de forma científica los discursos de los integrantes del entorno laboral además de estudiar las condiciones donde se desarrolla el trabajo con el objetivo de hacer muchos planes estratégicos en cual permitirá poder superar de forma libre y ordenada todos procesos y los factores negativos en el descubren y el cual afecta horizontalmente el comportamiento, eleva el recurso humano y principalmente eleva la productividad (20).

Es muy importante tener en cuenta que para el análisis y el estudio sobre el tema de clima organizacional la evaluación de la situación existente y actualizada, lo cual nos va a permitir conocer de forma directa la apreciación que tiene en empleado sobre la empresa en la cual trabaja, así también dará las perspectivas posteriores a los diversos asuntos conflictivos a raíz de altercados de la propia organización, su entorno y los factores humamos. Para el progreso organizacional se tiene que efectuar algunas intervenciones con la finalidad generar mediciones primitivas para tener una pesquisa muy imparcial y fundamentada que vaya sin juicios y se emitan ya sea anecdóticas o intuitivos. En ese sentido las ideas y el clima organizacional es fundamental porque: nos dará lineamientos particulares de la organización que va a favorecer la propia imagen y proporcionara mayor realce a los integrantes de manera interna o externa es por ello que se analiza y luego se diagnostica por varias razones.

Es importante examinar los orígenes de las discrepancias, de la insatisfacción o de estrés que agudizan el desarrollo aptitudes positivas y negativas frente a las situaciones de la institución. Es por ello que se inicia y se sostiene la reputación del líder frente al 
administrador sobre todo de las cosas particulares en donde debe intervenir, es por ello que se debe estudiar, analizar y luego tener un diagnóstico certero para poder determinar los factores que dificultan el correcto funcionamiento de la empresa, lo cual permite alcanzar los objetivos trazados (MINSA, 2009, P. 22). Características del clima organizacional. Pintado, (2010), afirma que las características del clima organizacional son los motivos siguientes: Al clima organizacional lo define las variables por ello son aspectos que adquieren correlación con el ambiente de trabajo. El establecimiento prestador de salud tiene una cierta condición en todos los cambios que tiene límites y son graduados, es por ello que genera una estabilidad sin sufrir muchas permutas en la toma de decisiones a futuro. El clima laboral puede tener un impacto directo sobre la conducta y comportamiento de los integrantes de la organización sin ninguna limitación, lo que genera una precaria condición de la conducción organizacional. El clima laboral desestabiliza y tiene relación directa con el compromiso de los integrantes de la organización. El clima laboral es visto por el nivel de conducta y las actitudes de los empleados.

El clima organizacional se ve comprometido por todas las variables como estructurales, las políticas, la dirección, además de los planes de gestión, el despido y los procedimientos de contratación. La no presencia del personal y las rotaciones excesivas son indicios de un pésimo clima laboral, además de la incapacidad e ineficacia para dirigir y conducir, así como la falta de control, las tardanzas, la desmotivación de sus miembros, la falta de respeto, el no respeto de las normas, etc. Hay una relación vertical entre el mal y buen clima organizacional con un hostil trabajo. Si se puede cambiar el clima organizacional, pero es importante hacer muchos cambios en las variables para que pueda ser permanente (p. 12). Los cambios serán posibles si se logran que los agentes seas educados y que no se contaminen con la gente de mala reciprocidad y con mucha incertidumbre del mismo sistema (Gibson, Ivancevich, Donnelly, 1987, p. 18). Consecuencia del clima organizacional. Según el Ministerio de Salud (MINSA) tiene una definición que el buen o mal clima organizacional es producto de las implicaciones negativas y generara un nivel mal estado de la organización que son fijados por la percepción de sus integrantes. Los efectos positivos que genera el clima laboral son: poder, productividad, satisfacción, innovación, afiliación, logros conjuntos, baja rotación, etc. Y dentro de los factores nocivos están: el ausentismo, la nula innovación, la alta 
rotación, la inadaptación y la poca productividad. El clima en unión con las características y las estructuras propias de cada individuo conforman, gobierna un sistema independiente que es sumamente eficiente, es por ello que en un excelente clima organizacional impulsara el desarrollo empresarial y generara una cultura organizacional con bases sólidas, buenas expectativas, valores, principios con la finalidad de la mejora continua de los miembros de la organización (p. 20).

La resistencia organizacional. Hellriegel, D. y Slocum, J. (2014), en referencia a la resistencia organizacional ellos manifiestan que la organización es la más eficaz cuando realizan muchas tareas de rutina y es por ello que se tiende a recuperar de manera más asertiva cuando se lleva a cabo los trabajos por primera vez y más principales causas a la resistencia son: Diseño de la organización: Todas las instituciones y organizaciones requieren de una confiable y continua estabilidad para que puedan "mejorar su desempeño" además el autor señala que el personal debe tener muchas funciones específicas para poder cumplir las funciones principales y poder realizar bien su trabajo por lo que está sujeta a lo que pueda provocar la firmeza el cambio de la organización. Cultura organizacional: Se define como el desempeño principal para el cambio, es por ello que no es fácil modificarse y es por eso que tiene posibilidad de cambio y no existe mayor resistencia. Limitaciones de recurso: son algunos individuos a los que siempre quieren pertenecer al grupo de estatus y se resiste a dejarlo, sin embargo, otras personas si pueden cambiar si tuvieran los recursos ya sea el capital, y la gente capacitada, en tal sentido los directivos y los empleados los que identifican el cambio que se podría hacer, sin embargo, por limitación de presupuesto dejan dichos cambios. En tal sentido, en estas épocas todas las organizaciones tienen ciertos mecanismos el cual ejercen una regulación en los procesos y sus procedimientos, lo que conlleva a tareas rutinarias para el control del personal y cuando se necesita realizar varios cambios a los actores responsables a quien lo facilita (p. 35).

Tipos de clima organizacional. García, M., Ibarra M. (2009), lo definen en dos grandes grupos de clima organizacional y a cada actor el cual tiene subdivisiones particulares y dentro de ellas tenemos: Autoritarismo explotador: Sistema I, Según este clima demuestra que la orientación de la organización no tiene ninguna seguridad en los trabajadores, es por ello que la mayor parte de los decretos y el cumplimiento de las metas que se plantean en relación al clima interior de la empresa y las ordenes son únicamente 
de forma jerárquica y dictatorial. Los integrantes trabajan un ambiente de terror, con ciertas amenazas, algunas recompensas lo cual influye directamente en el nivel psicológico dando muestra de seguridad. Según este tipo se presenta un ambiente amigable y muy simpático en la comunicación de la orientación con los obreros que ya tiene procedimientos establecidos. Autoritarismo paternalista: Sistema II, Según nos describe este es un clima en el cual la dirección tiene una mayor confianza entre los integrantes de la organización, es como el maestro y su alumno es por ello que casi todas las decisiones o toman los altos mandos jerárquicos, pero otros lo toman los niveles más inferiores; es acá donde surgen los premios y las sanciones como método para incentivar a los trabajadores. En este clima donde las necesidades sociales adoptan un rol fundamental dentro de la organización es por ello que se tiene la idea de laboral en un ambiente adecuado, tranquilo, estable y estructurado.

Autoritarismo participativo: Sistema III, De acuerdo a este prototipo de clima la dirección jerárquica de la organización es la que tiende a evolucionar dentro de un ambiente democrático en dónde se tiene la plena y más sincera confianza entre los integrantes de la organización, sin embargo, las decisiones y los lineamientos y las decisiones lo dan las altas jerarquías, pero sin embargo acá los permiten a los súbditos a que tomen algunas decisiones. En referencia al dialogo existente podemos precisar que es de una manera descendente donde existe recompensa, castigo, con la finalidad de motivar a los miembros, así como para satisfacer necesidades extras laborales para generen un excelente clima laboral entre compañeros y así ser muy activo y dinámico con el compromiso de lograr las metas trazadas. Participativo: Sistema IV-participación grupal, Este es el tipo de clima donde la dirección tiene el control además de la confianza en sus empleados para ello existe diversos procesos para tomar las disposiciones y las riendas de la organización y se integra por los niveles. Es acá donde el dialogo no solo es de forma horizontal ni vertical sino también de forma literal, siempre y cuando los empleados estén plenamente incentivados y motivados en la participación en cuanto están estrechamente comprometidos con el pleno logro de los objetivos además para el mejoramiento de los procesos de trabajo con la mira de obtener un alto rendimiento y productividad para alcanzar metas propuestas (p. 40).

Teorías del Clima Organizacional. Martin (1998), el cual fue mencionado por López (2010) la cual hace alusión a las múltiples corrientes como: los humanistas, los críticos, 
los sociopolíticos y los estructurales. Entre los más sobresalientes están los sociopolíticos que manifiestan que el clima organizacional es un concepto general y muy complejo que intenta agrupar múltiples componentes como valores, normas, reglas, para un óptimo desempeño de la organización (p. 28) es por ello que propone: La teoría de clima organizacional es aquel que nos permite estudiar a fondo en términos más prácticos de causa y efecto según la condición en que se vive en la empresa, además se puede investigar a fondo el rol que cumple las variantes que lo conforman al clima empresarial, la cual se visualiza, se sostiene que influye directamente en los 3 grupos según las variables de estudio a) la primera son las cimientos de la organización y administración en ella tenemos las decisiones, las reglas, normas, las competencias y también las actitudes. b) Las variables medias son el reflejo del medio interno y la condición de salud en que se encuentran la institución ya sea la actitud, los procesos organizacionales, la motivación, etc. y c) la última variable es la consecuencia de las antes mencionadas y que impacta directamente a la institución en las ganancias, la pérdida o la productividad (p. 28).

Brunet (2014), señalado por López (2013) manifiesta que: según la teoría de Likert, el cual permite conocer los términos precisos de causa y efecto del ambiente del clima que se analizan y que nos permite estudiar el rol que cumple las variables. En su postulado de sistemas, según Likert, nos plantea que la conducta de los trabajadores es generada como parte del comportamiento del personal administrativo además de los escenarios organizacionales que se toman mediante la percepción, las falsas promesas, los valores, las capacidades y las esperanzas Demuestra también que la rebeldía individual ante cualquier situación, lo que demuestra que el conocimiento ve las cosas y no la realidad intrínseca. (p. 28). Para Martín (1998), el cual fue citado por Edel (2007), describe que para la escuela estructuralista: El clima se origina mediante aspectos objetivos del contexto laboral, tal como la concentración en la toma de medidas de acuerdo a que la organización requiera el nivel jerárquico de la autoridad, además del tipo de tecnología la cual se utiliza y por último debe haber un comportamiento personal.

En tal sentido, no se obstaculiza que influya la personalidad individual sino en la determinada aceptación del concepto de los sucesos ocasionados en la institución, sino que se basa específicamente en los elementos firmes de una naturaleza sólida y contundente. Toda institución tiene un espacio en el cual se desarrolla las actividades 
sociales más importantes del personal y donde por último se distingue la relación más cercana entre personas de niveles superiores y los empleados eso es según la teoría humanista. Por ello que ellos afirman que la definición de clima organizacional es un conglomerado de apreciaciones generales que los integrantes tienen sobre el ambiente de trabajo y eso se ve reflejado en la vivencia e interacción particulares de cada una las personas que laboral (p. 52). Para la corriente sociopolítica el clima organizacional se define como la encarnación de una percepción muy universal que engloba muchos aspectos de la organización y se describe a las actitudes incipientes, a las normas, los sentimientos y los valores.

Dimensiones del clima organizacional. Se puede definir como aquellas características eficaces en una organización que tienen un vínculo directo en la conducta individual de los trabajadores. Goncalves, A. (2000), indica que entre las opciones para analizar el tema de clima organizacional, es necesario citar la técnica desarrollada por Litwin y Stinger el cual utiliza un interrogatorio y se usa con todos los integrantes de la institución y en su trabajo de investigación indica que estas dimensiones son: estructura, desafío, recompensa, responsabilidad, cooperación, estándares de identidad y conflicto entre sus miembros (www.Geocities.ws). Estructura Organizativa. Es la apreciación que tienen los integrantes laborales, en referencia a los tramites, reglas, procedimientos y otras actividades para generen un excelente desarrollo del trabajo. Responsabilidad. Verifica el sentido de compromiso del trabajador, que a la vez viene a convertirse en su propio jefe en el trabajo. Los integrantes de la organización tienen independencia en la toma de disposiciones relacionas a alguna actividad realizada de una manera responsable.

Relaciones. Viene a ser la perspicacia por parte de un grupo de integrantes de la institución en referencia al ambiente laboral agradable y con ejercicio de buenas actividades entre compañeros, con dependientes y jefes. Un excelente ambiente laboral tiene su origen en las relaciones positivas, confortables, firmes y estables con todos los integrantes de la empresa. Cooperación. Es aquella impresión que generan los empleados de la empresa sobre el aspecto y sobre todo cuando existe una fuerza externa que auxilia a los directivos u otro parte del personal dependiente de la organización (p. 39). Satisfacción Laboral. Es la impresión única que ocasiona que cada persona sea producto de la elaboración de alguna cosa que ella anhelaba para cumplir sus propósitos profesionales (Davis y Newstrom, 2003, p. 27). El bienestar en el trabajo lo determinan 
como aquella impresión que se experimenta al poder alcanzar la armonía entre una escasez o grupo de escaseces y el camino a la meta, en otras palabras, es el completo compromiso que tiene el trabajador frente a su trabajo, es decir estar orgulloso es estar complacido, contento y feliz (Locke, 1976, p. 1).

El bienestar en el trabajo, también se puede llamar de manera general, como la actitud del individuo hacia su empleo. Los trabajos que las personas desarrollan son mucho más que las acciones realizadas, puesto que necesita mayor laso de comunicación con los pares y luego con los gerentes para poder cumplir con las reglas y normas establecidas de acuerdo a su política, los estándares y poder convivir con la condición inhóspita del trabajo (Hannoun, 2001). Definiciones de satisfacción laboral. Márquez, G. (2001), lo describe como la condición del empleado en relación a su proporcionado esfuerzo, esta condición está fundamentada en los valores, costumbres y creencias donde el trabajador es quien es el centro de las actividades laborales. Las actitudes son manifiestas en el grupo por las particularidades y las percepciones del empleado (p. 83). Blum M. y Naylor J. (1982), se refiere a la satisfacción del trabajo como efecto de las múltiples condiciones que tienen los trabajadores, dichas condiciones hacen una estrecha dependencia con el trabajo y se representa en la figura como, por ejemplo: el ascenso, los salarios, la supervisión, las condiciones donde se desarrolla en trabajo, la supervisión, el desenvolvimiento en el trabajo, la resolución eficaz de los problemas, el trato justo, etc. Chiavenato, I. (2009), indica que la satisfacción en el centro laboral tiene que ver con el nivel de vida en el ambiente laboral y nos hace referencia a como el personal se siente dentro de la institución, el nivel de bienestar en el centro laboral conlleva a generar mayor competencias para poder adquirirlos, es por ello que se tiene que tener estabilidad en el clima organizacional y además de tener un ambiente saludable para poder motivar a los integrantes y a forjar mayor compromiso. En resumen, la satisfacción en el trabajo no establece una conducta entre sí, más bien se refiere a la actitud que toman los integrantes frente a la empresa u organización (p. 30).

Gibson J, Ivancevich J, Donnelly J. (1987), mencionan que la satisfacción en el trabajo, se logra por la predisposición que las personas que planean acerca de sus funciones de trabajo, es decir, todo está basado en los elementos referentes al espacio laboral en el cual se desarrolla como por ejemplo: el estilo y la dirección organización, los procedimientos y las políticas, además del agrado de los grupos laborales en el ambiente de trabajo, los 
beneficios y las condicionen en las que se encuentran los trabajadores (p. 18). Factores que determinan la satisfacción laboral. Davis K, Newstrom J. (1997), considera que los elementos más importantes son: Un buen sistema de recompensas. Buenas condiciones de trabajo (clima e infraestructura). Contribución entre colegas y demás. Compatibilidad de personalidades en los puestos de trabajo. Destrezas poseídas por el empleado mediante desafíos positivos (27). Robbins, S. (1997), refiere que los factores primordiales para conducir a una satisfacción personal dentro del trabajo son: tener un empleo retador desde el punto de vista intelectual, que tenga y haya buenas recompensas igualitarias, buenas condiciones y ambientes de trabajo y que tenga respaldo, que los colegas siempre apoyen y que se asemejen en la personalidad - puesto. En otro punto señala que la satisfacción en el centro laboral implica felicidad, productividad, ausentismo de rotación (55). Hannoun G. (2011), se refiere a la insatisfacción laboral como una causa principal para la baja productividad de los empleados con respecto al rendimiento de la organización, por lo que su deber de las empresas son tener trabajadores satisfechos profesionalmente y salarialmente. Pero esa insatisfacción laboral se puede generar un sin número de acontecimientos que afectan y alteran negativamente a los empleados y esto causa una intensa insatisfacción que se traduce en un descontento y un deseo de cambiar o abandonar el trabajo. Y esos factores que lo causan son: Salario bajo. Esto es para el empleado este más contento en su centro laboral es por ello que tenga que tener un sueldo considerable. Pésima relación entre compañeros o jefes. La mala correlación puede ser causal de enojos y causa celos, envidias y conductas negativas que llevan a un clima tenso. Nula o escasa posibilidad de promoción. Cuando un trabajador es ambicioso y tiene aspiraciones profesionales y lo estancan en un puesto inferior, se siente incómodo al ver cómo transcurre el tiempo y no asciende en la organización, la persona esta incomoda pues no es lo que esperaba del trabajo y eso producirá desequilibrio en el clima laboral. Personas inseguras. Son aquellas con escasa confianza en sí mismas y tienen aptitudes que alejan del buen desempeño del trabajo y por ello no se creen capaces de desarrollar cientos actividades y no de adaptan al trabajo.

Dificultad para adaptarse en el ambiente laboral. Existe empleados que son poco pacientes y siempre cambian de empleo porque se aburren o desean alcanzar otros objetivos profesionales y suelen estar siempre insatisfechos en el trabajo. Malas condiciones laborales. El descontento laboral es consecuencia de una pésima política de la 
organización, lo material, la infraestructura, la precariedad, etc. Circunstancias personales y laborales. Son los aspectos que tiene que ver con la experiencia, el sexo, el grado de estudios, la edad, la cultura, las costumbres, etc que alteran y determinan el empleo a desarrollar lo que genera un descontento en el personal (p. 20). Dimensiones de la satisfacción laboral. Existen diversas dimensiones que se fueron asociando con la satisfacción del empleo. Gibson, J., Ivancevich, J. y Donnelly, J. (1987), en su trabajo de investigación indica que estas dimensiones son: paga, trabajo, oportunidad de ascenso, jefe y colaboradores (p. 18). Remuneración. Es el importe recibido y la impresión de equidad de una retribución salarial. Una organización debe retribuir a su personal laboral por su eficiencia y los escenarios laborales que da esa eficiencia como la: responsabilidad interna, social y empresarial y a través de esta innovación, mejorará el esfuerzo y desempeño de los trabajadores. Oportunidad de ascenso: siempre debe haber una presencia de ocasiones para poder ascender (escalar puestos de trabajo). La mejor manera de conseguir un ascenso laboral es precisamente no pedirlo, un profesional debe tener claridad sobre por qué está en una empresa o organización, y sentir que está desarrollando un trabajo que lo motiva a crecer como profesional y también como persona, pero lo primordial es que tu Centro Laboral reconozca tu desempeño, y de esa forma sabrás si cumples con los requisitos para ascender.

Trato con jefe. La persona que cumple la función de ser un jefe, principalmente debe mostrar interés por los empleados. Sin embargo, casi la mayoría de los que tienen ese cargo suelen tener comportamientos alterados que alteras a los empleados, obligándolas a cumplir muchas tareas que no competen al trabajador. El jefe debe fomentar una mejor comunicación, planificar y organizar mejor su área y disminuir la rotación de su equipo. con Colaboradores. Deben tener cierto grado de compañerismo, apoyo y capacidad los integrantes del centro laboral, porque siempre existe y envidias dentro de los profesionales, los mismos trabajadores hacen que entre ellos haya amenazas internas. En conclusión, la pésima relación en el centro laboral hace que las integrantes tengan el deseo de renunciar al empleo (p. 18). Fuentes de satisfacción en el puesto. Lut, F. (2008), manifiesta que hay distintos elementos que repercuten en la satisfacción laboral, cita al siguiente ejemplo que, si los estudiantes universitarios coincidían con un empleo, dicha correspondencia hacia predecir que habrá satisfacción laboral, sin embargo, existe muchas influencias y se detalla en cinco dimensiones (p. 27). El trabajo mismo. El mismo 
ambiente donde se desarrolla el trabajo es también la principal herramienta para lograr un buen bienestar laboral, a un nivel experto incluyen un trabajo interesante y desafiante (p. 27). El pago o remuneración. Se reconoce que el salario es un factor significativo, aunque cognitivamente complicado y multifactorial del bienestar profesional. El dinero no solo apoya a los individuos a complacer las prioridades esenciales sino además de complacer las escaseces de nivel más alto, es muy frecuente que los trabajadores consideren que el salario es un reflejo de su contribución con la institución (p. 27).

Oportunidades de promoción. Se define como aquellas que parecen tener efecto cambiante en el bienestar profesional, pues esto se debe a que las personas alcanzan diversos estilos y tiene bastante ganancia de forma adicional. Los ejemplos más claros son: las personas que fueron promovidos en base a su experiencia un goce en el trabajo. Así como las personas que son promovidos en base a su desempleo laboral, en otro acápite, por ejemplo, un aumento salarial de 5\% no es complaciente como las de un $15 \%$. Tal diferencia nos conlleva a exponer que las promociones de directivos son más placenteras que las ofertas que se hace a los empleados de un nivel inferior. Los trabajadores que laboren en el nuevo modelo, son perfectamente conocedores de las promociones habituales que no se encuentran favorables, pero tampoco son las más anheladas. El ambiente laboral y las circunstancias (p.27). Supervisión. La fiscalización es otro inicio moderado y trascendental en la satisfacción laboral. Sin embargo, ahora existen dos estilos de dimensiones de la supervisión. La primera está orientada a los trabajadores y se mide según el grado con el que un superior adquiere un beneficio individual. Se comunica siempre en acciones de supervisar el desempeño del trabajador. Para proporcionar diversos consejos, ayuda mutua y comunicación con él a nivel individual y grupal. La siguiente dimensión es la colaboración y dominio que es simbolizada por los dirigentes el cual permiten a los empleados intervenir de forma autoritaria en las decisiones que dificultan a los propios compañeros; varios autores afirman que este método genera un mayor bienestar entre trabajadores de una institución (p. 27).

Grupo de trabajo. El grupo de trabajo tiene un resultado en el bienestar laboral, los integrantes o colegas de equipos, cooperadores, amistosos son un el principal comienzo del bienestar personal de los empleados. Un equipo de trabajo, específicamente cuando se refiere a un "grupo unido" es cuando tiene un principio de consejo, apoyo, soporte y 
sobre todo el bienestar de empleados. El estudio muestra que los grupos quieren demasiada libertad en la toma de decisiones esto conllevara a tener un trabajo con más goce. Un excelente ambiente conlleva a que su trabajo sea más atractivo (p. 27). En otro sentido, si hay la condición contraria (no es tan fácil llevarse bien con las integrantes de la institución), este factor podría producir un factor nocivo, el estudio señala que a través de la cultura indica que si los integrantes se aferran a los grupos en general y a los equipos que son auto-dirigidos en forma particular, ellos se van a sentir menos satisfechos que si aceptaran ser parte de ellos. Condiciones de trabajo. Los escenarios de trabajo generan una reacción moderada en referencia al concepto de satisfacción laboral, es por ello que, si los escenarios laborales son óptimos, por ejemplo: un ambiente agradable, limpio, atractiva que a la persona les va a complacer poder desarrollar su trabajo.

Si los escenarios de trabajo son defectuosos como, por ejemplo: un lugar cálido, ruidoso, desaseado. A los trabajadores se les va a dificultar poder desarrollar los trabajos encomendados, dicho de otra forma, el comportamiento de las condiciones laborales es igual al de los integrantes del grupo hay menor probabilidad de que surjan inconvenientes (p.22). Desempeño de tareas. Es la calificación con el cual se relaciona el empleado con sus labores diarias en el ambiente donde trabaja. El trabajo en el ámbito de la organización es el cumplimiento y ejecución de las destrezas y habilidades adquiridas en el centro de trabajo con la finalidad de un eficiente manejo de las funciones encomendadas (UrbinaLaza, 2005, p. 1). Relaciones interpersonales. Lo definen como la comunicación de los trabajadores del ámbito de la salud al interior de la unidad prestadora de salud, de los trabajadores con el paciente. Las excelentes relaciones inter personales generan más confianza y mayor credibilidad, mediante las acciones, demostraciones, la empatía y sobre todo la responsabilidad (Proyecto Salud y Nutrición Básica, 1996, p. 1). Beneficios laborales y remunerativos. La remuneración (el salario, el sueldo, etc.) es la pensión que recibe el trabajador a cambio de su trabajo (Werther, 2000, p. 18). Ambiente Laboral: Se le denomina ambiente laboral a uno de los elementos más valiosos en el día a día de la empresa, pero, sin embargo, las diversas características que lo determinan son arduos de entender. Estos pueden ser de naturaleza intangible o tangible y lo que se ha demostrado que intervienen drásticamente en la producción y en la vida privada de los trabajadores. Como problema general: ¿Cuál es el nivel de clima organizacional y la satisfacción laboral de los colaboradores del área asistencial del Hospital II - E Banda de Shilcayo, 
2018?, asimismo los problemas específicos ¿Cuál es el nivel de clima organizacional según las dimensiones realización personal, supervisión, condiciones laborales, involucramiento laboral de los colaboradores del área asistencial del Hospital II - E Banda de Shilcayo, 2018?, ¿Cuál es el nivel de satisfacción laboral en los colaboradores del área asistencial del Hospital II - E Banda de Shilcayo, 2018?, ¿Cuál es la dimensión del clima organizacional de mayor relación con la satisfacción laboral de los colaboradores del área asistencial del Hospital II - E Banda de Shilcayo, 2018? Como objetivo general fue determinar la relación entre el clima organizacional laboral del área asistencial del Hospital II - E Banda de Shilcayo, 2018. Del mismo modo, los objetivos específicos: (i) Identificar el nivel de clima organizacional según las dimensiones realización personal, comunicación, involucramiento laboral, supervisión y condiciones laborales en los colaboradores del área asistencial del Hospital II - E Banda de Shilcayo, 2018. (ii) Evaluar el nivel de satisfacción laboral en los colaboradores del área asistencial del Hospital II - E Banda de Shilcayo, 2018. (iii) Identificar la dimensión clima organizacional de mayor relación con la satisfacción laboral en los colaboradores del área asistencial del Hospital II - E Banda de Shilcayo, 2018. En cuanto a la Hipótesis general, se presentó de la siguiente manera: Hi: existe relación significativa entre el clima organizacional y la satisfacción laboral de los colaboradores del área asistencial del Hospital II - E Banda de Shilcayo, 2018. Asimismo, las hipótesis específicas: (H1) el nivel de clima organizacional según las dimensiones realización personal, supervisión, involucramiento laboral, comunicación y condiciones laborales en los colaboradores del área asistencial del Hospital II - E Banda de Shilcayo, 2018. (H2) el nivel de satisfacción laboral en los colaboradores del área asistencial del Hospital II - E Banda de Shilcayo, 2018. (H3) la dimensión del clima organizacional de mayor relación con la satisfacción laboral Hospital II - E Banda de Shilcayo, 2018.

\section{MÉTODOLOGIA}

La investigación realizada es de tipo básica descriptiva no experimental, ya que la línea de desarrollo de investigación estuvo dirigida a incrementar el conocimiento de las dos variables de estudio, es por ello que se ha recolectado la información necesaria para poder evaluar su real comportamiento observado de las dos variables sin ninguna alteración por el investigador (Hernández, Fernández y Baptista, 2014). El diseño de estudio es fue descriptivo correlacional ya que se estudió a fondo las variables, cuya finalidad es describir 
su comportamiento dentro de la realidad en el cual se desarrolla para luego poder afirmar si la variable de estudio clima organizacional se relaciona con la variable satisfacción laboral del personal asistencial (Hernández, Fernández y Baptista, 2014). Las variables de estudio fueron: $\mathrm{V}_{1}$ : variable clima organizacional y $\mathrm{V}_{2}$ : variable satisfacción laboral La población estuvo constituida por los 147 colaboradores del área asistencial del Hospital II-E Banda de Shilcayo - 2018. La muestra se calculó a través de una formula estadística de población conocida en base a los registros proporcionados por el área de estadística, siendo un total de 119 colaboradores. Se hizo un muestro probabilístico por tipo de personal, para ello para determinar la muestra se realizó la lista de personal que facilitó el área de recursos humanos del Hospital siendo seleccionados 7 médicos generales, 1 médico especialista, 25 enfermeros, 16 obstetras, 2 odontólogos, 1 biólogo/microbiólogo, 1 tecnólogo médico, 1 nutricionista, 1 psicólogo, 1 asistenta social, 46s técnico de enfermería, 4 técnicos de laboratorio, 1 técnico administrativo, 1 técnico informático, 1 técnico en computación, 1 técnico de laboratorio, 1 digitadores, 3 choferes, 1 trabajador de servicio, 1 técnico de farmacia, 1 inspector sanitario, 1 auxiliar de enfermería. El estudio utilizó como técnica la encuesta. Los instrumentos que se aplicaron en el estudio fueron 2 cuestionarios con preguntas cerradas categorizadas en una escala tipo Likert adaptado según el Job Diagnostic Survey de Hackman y Oldham, uno para medir la variable clima organizacional y el segundo instrumento para medir la variable de satisfacción laboral. El instrumento $\mathrm{N}^{\circ} 1$ : Escala sobre clima organizacional (CL-SPC), el cual fue creado y diseñado por la Psicóloga Sonia Palma Carrillo, docente de la Universidad Ricardo Palma (Lima, Perú), en el instrumento se detalla cinco factores que influyeron en el análisis estadísticos y cualitativo y son: Realización personal (Autorregulación): los ítems que lo constituyen son: 1,2,3,4,5,6,7,8,9 y 10. Involucramiento Personal: los ítems: 11, 12, 13, 14, 15, 16, 17, 18, 19 y 20. Supervisión: los ítems son: 21, 22, 23, 24, 25, 26, 27, 28, 29 y 30. Comunicación: los ítems son: 31, 32, 33, 34, 35, 36, 37, 38, 39 y 40. Condiciones laborales: los ítems son: 41, 42, 43, 44, 45, 46, 47, 48, 49 y 50. El nivel general del clima organizacional, tienen una calificación de 1 a 5 puntos de un total de 250 puntos como puntaje más alto en la escala general y por ello de 50 puntos para cada componente. Dicha escala cuenta con 50 ítems que están representan a las dimensiones, por ende, por cada ítem; este está conformado por 5 alternativas y cuyos valores son: ninguno o nunca 1 , poco 2 , regular o algo 3 , mucho 4 , 
todo o siempre 5. Las clases establecidas que son consideradas por la herramienta están orientadas en la calificación directa que se adoptara a un criterio que de acuerdo a un más puntaje es mucho más probable una apreciación del ambiente en el cual trabajan y si es mejor puntaje se interpreta de manera contraria Muy favorables 42-50 = 210-250; favorable 34-41 = 170-209; media 26-33 = 130-169; Desfavorable 18-25 = 90-129; muy desfavorable $10-17=50-89$.

El segundo instrumento se trata sobre la satisfacción laboral SL-SPC, diseñado por la Psicóloga Sonia Palma Carrillo, profesora de la Universidad Ricardo Palma (Lima, Perú), es una herramienta que tiene un total de 36 ítem que son referidos a todas las dimensiones, en donde cada ítem está conformado por cinco alternativas y se califica y se valora de la siguiente manera: Totalmente de acuerdo 1, desacuerdo 2, indiferente 3 , de acuerdo 4, totalmente de acuerdo 5. El puntaje general es producto de la suma de las puntuaciones que son logradas mediante las respuestas para cada ítem, la calificación fluctúa entre 36 y 180, todas estas calificaciones son elevados y por ello simboliza una satisfacción laboral frente al empleo; en cambio las calificaciones bajas son una insatisfacción laboral frente al trabajo. Esta es una escala que mide la satisfacción laboral los diferentes grados: Satisfacción laboral muy alta 168 a 180 puntos, alta satisfacción laboral 149 a 167 puntos, mediana satisfacción laboral 112 a 148 puntos, baja satisfacción laboral 93 a 111 puntos, sin satisfacción laboral menor o igual a 92 puntos.

Todos los datos que se obtenidos de los colaboradores del área asistencial mediante el cuestionario se precisaron y se tabularon mediante el paquete estadístico IBM - SPSS, en la versión 23, en español y la versión de Windows 10, lo que permitirá la aplicación de pruebas estadísticas descriptivas (frecuencias y porcentajes) y la prueba estadística inferencial de la Correlación de Pearson, el cual nos facilitó con las exactitud la verificación de la plantación de nuestra hipótesis en el estudio. Como aspectos éticos tuvo en cuenta todas las normas y además de los códigos de ética y sobre todo respetando estrictamente la dignidad y la identidad de todos los colaboradores del área asistencial que han participado en dicho estudio, por lo tanto, se perpetuara la confidencialidad de toda la información y así proteger la identidad.

\section{RESULTADOS Y DISCUSIÓN}

3.1. Resultados Identificar el nivel de clima organizacional según la dimensión de realización personal, involucramiento laboral, comunicación, supervisión, condiciones 
laborales en los colaboradores del área asistencial del Hospital II - E Banda de Shilcayo, 2018

\section{Tabla 1}

Nivel de clima organizacional según las dimensiones.

\begin{tabular}{|c|c|c|c|c|c|c|c|c|c|c|c|c|}
\hline \multirow{2}{*}{ Dimensiones } & \multicolumn{2}{|c|}{$\begin{array}{c}\text { Muy } \\
\text { Desfavorable } \\
\end{array}$} & \multicolumn{2}{|c|}{ Desfavorable } & \multicolumn{2}{|c|}{ Media } & \multicolumn{2}{|c|}{ Favorable } & \multicolumn{2}{|c|}{$\begin{array}{c}\text { Muy } \\
\text { favorable }\end{array}$} & \multicolumn{2}{|c|}{ Total } \\
\hline & $\mathbf{f i}$ & $\%$ & fi & $\%$ & $\mathbf{F i}$ & $\%$ & $\mathrm{Fi}$ & $\%$ & fi & $\%$ & fi & $\%$ \\
\hline $\begin{array}{l}\text { Realización } \\
\text { Personal }\end{array}$ & 13 & $10.9 \%$ & 49 & $41.2 \%$ & 46 & $38.7 \%$ & 11 & $9.2 \%$ & 0 & $0 \%$ & 119 & $100 \%$ \\
\hline $\begin{array}{l}\text { Involucramiento } \\
\text { personal }\end{array}$ & 1 & $0.8 \%$ & 21 & $17.6 \%$ & 54 & $45.4 \%$ & 40 & $33.6 \%$ & 3 & $2.5 \%$ & 119 & $100 \%$ \\
\hline Supervisión & 3 & $2.5 \%$ & 45 & $37.8 \%$ & 56 & $47.1 \%$ & 15 & $12.6 \%$ & 0 & $0 \%$ & 119 & $100 \%$ \\
\hline Comunicación & 4 & $3.4 \%$ & 47 & $39.5 \%$ & 59 & $49.6 \%$ & 8 & $6.7 \%$ & 1 & $0.8 \%$ & 119 & $100 \%$ \\
\hline $\begin{array}{l}\text { Condiciones } \\
\text { Laborales }\end{array}$ & 5 & $4.2 \%$ & 47 & $39.5 \%$ & 54 & $45.4 \%$ & 13 & $10.9 \%$ & 0 & $0 \%$ & 119 & $100 \%$ \\
\hline
\end{tabular}

Fuente: base de satos fue elaborado por el autor

La tabla 1 muestra el número y porcentaje de colaboradores del área asistencial del Hospital II-E Banda de Shilcayo, 2018, es clima organizacional medio con el 50,4\% y el $37,0 \%$ lo califica como "desfavorable" según escala valorativa de la variable clima organizacional y sus dimensiones, se evidencia que el $41,2 \%$ de los colaboradores refieren que el clima organizacional según la dimensión es desfavorable; el 45,4\%, $47.1 \%, 49,6 \%$ y $45.4 \%$ refieren que en la dimensión involucramiento personal, supervisión, comunicación y condiciones laborales del clima organizacional es media respectivamente.

\section{Tabla 2}

Nivel global de clima organizacional

\begin{tabular}{lccc}
\hline \multicolumn{1}{c}{ Nivel } & Escala & fi & $\%$ \\
\hline Muy favorable & $210-250$ ptos. & 0 & $0.0 \%$ \\
Favorable & $170-209$ ptos. & 12 & $10.1 \%$ \\
Media & $130-169$ ptos. & 60 & $50.4 \%$ \\
Desfavorable & $90-129$ ptos. & 44 & $37.0 \%$ \\
Muy desfavorable & $50-89$ ptos. & 3 & $2.5 \%$ \\
Total & & 119 & $100.0 \%$ \\
\hline
\end{tabular}

Fuente: base de datos fue elaborado por el autor 
La tabla 2 muestra el clima organizacional que perciben los colaboradores asistenciales del Hospital II-E Banda de Shilcayo, según escala valorativa de la variable clima organizacional. Se evidencia que, el 50,4\% se ubica en clima organizacional "media" y el 37,0\% lo califica como "desfavorable". Solo el 10,1\% de los colaboradores refiere un clima organizacional "favorable".

\section{Tabla 3}

Satisfacción laboral en los colaboradores

\begin{tabular}{lccc}
\hline \multicolumn{1}{c}{ Dimensiones } & Escala & fi & $\%$ \\
\hline Satisfacción laboral muy alta & $168-180$ ptos. & 1 & $0.8 \%$ \\
Alta satisfacción laboral & $149-167$ ptos. & 2 & $1.7 \%$ \\
Mediana satisfacción laboral & $112-148$ ptos. & 59 & $49.6 \%$ \\
Baja satisfacción laboral & $93-111$ ptos. & 40 & $33.6 \%$ \\
Sin satisfacción laboral & $36-92$ ptos. & 17 & $14.3 \%$ \\
\hline
\end{tabular}

Fuente: base de satos fue elaborado por el autor

La tabla 3 muestra la satisfacción laboral que presenta el colaborador asistencial del Hospital II-E Banda de Shilcayo, según escala de calificación de la variable satisfacción, se evidencia que, el $49,6 \%$ se ubica en "mediana satisfacción laboral" y el 33,6\% lo califica en baja satisfacción laboral. Solo 1 colaborador que representa el 0,8\% alcanzó satisfacción laboral muy alta. Relación entre el clima organizacional y la satisfacción laboral de los colaboradores del área asistencial del Hospital II-E Banda de Shilcayo, 2018. En este estudio para el análisis de la relación entre el clima organizacional y la satisfacción laboral de los colaboradores, es por ello que se aplicó la prueba de correlación de Pearson con un 95\% de nivel de confianza por ello que se desarrolló la prueba de hipótesis estadística. Dimensión del clima organizacional de la mayor relación con la satisfacción laboral de los colaboradores del área asistencial del Hospital II-E Banda de Shilcayo, 2018. 


\section{Tabla 4}

Resultados de la correlación de las dimensiones del clima organizacional y la satisfacción laboral.

\begin{tabular}{|c|c|c|c|c|c|c|c|}
\hline \multicolumn{2}{|c|}{ Variables y dimensiones } & 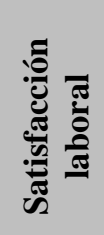 & 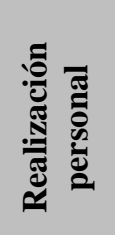 & 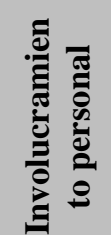 & 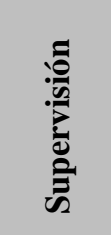 & ن̃. & 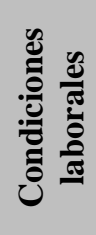 \\
\hline \multirow{2}{*}{$\begin{array}{l}\text { Satisfacción } \\
\text { laboral }\end{array}$} & $\begin{array}{l}\text { Coeficiente de } \\
\text { correlación }\end{array}$ & 1 &, 160 &, $434^{* *}$ &, $296^{* *}$ &, $344^{* *}$ &, $473^{* *}$ \\
\hline & Sig. (bilateral) & &, 083 &, 000 & 001 &, 000 & ,000 \\
\hline \multirow{2}{*}{$\begin{array}{l}\text { Realización } \\
\text { personal }\end{array}$} & $\begin{array}{l}\text { Coeficiente de } \\
\text { correlación }\end{array}$ &, 160 & 1 &, $493^{* *}$ &, $594^{* *}$ &, $567^{* *}$ &, $601^{* *}$ \\
\hline & Sig. (bilateral) & 083 & &, 000 &, 000 &, 000 &, 000 \\
\hline \multirow{2}{*}{$\begin{array}{l}\text { Involucrami } \\
\text { ento } \\
\text { personal }\end{array}$} & $\begin{array}{l}\text { Coeficiente de } \\
\text { correlación }\end{array}$ &, $434^{* *}$ &, $493^{* *}$ & 1 &, $655^{* * *}$ &, $593^{* *}$ &, $662^{* *}$ \\
\hline & Sig. (bilateral) &, 000 &, 000 & &, 000 &, 000 & 000 \\
\hline \multirow{2}{*}{ Supervisión } & $\begin{array}{l}\text { Coeficiente de } \\
\text { correlación }\end{array}$ & $296^{* *}$ &, $594^{* * *}$ &, $655^{* *}$ & 1 &, $766^{* *}$ & $659^{* *}$ \\
\hline & Sig. (bilateral) &, 001 &, 000 &, 000 & &, 000 &, 000 \\
\hline \multirow{2}{*}{$\begin{array}{l}\text { Comunicaci } \\
\text { ón }\end{array}$} & $\begin{array}{l}\text { Coeficiente de } \\
\text { correlación }\end{array}$ &, $344^{* *}$ &, $567^{* *}$ &, $593^{* *}$ &, $766^{* *}$ & 1 &, $751^{* *}$ \\
\hline & Sig. (bilateral) &, 000 &, 000 &, 000 & ,000 & &, 000 \\
\hline \multirow{2}{*}{$\begin{array}{l}\text { Condiciones } \\
\text { laborales }\end{array}$} & $\begin{array}{l}\text { Coeficiente de } \\
\text { correlación }\end{array}$ &, $473^{* *}$ &, $601^{* *}$ &, $662^{* *}$ &, $659^{* *}$ &, $751^{* *}$ & 1 \\
\hline & Sig. (bilateral) & 000 &, 000 &, 000 & ,000 &, 000 & \\
\hline
\end{tabular}

Fuente: Elaboración propia procesados en SPSS $v 25$ respecto a los puntajes totales obtenidos.

Se observa en la tabla 4 sobre la correlación de Pearson el nivel de significancia al 95\% con que concierne al objetivo específico 3, se evidencia que el grado de correlación entre las dimensiones del clima organizacionales relaciona directamente con la satisfacción laboral de los colaboradores del área asistencial del Hospital II-E Banda de Shilcayo, lo que indica que se obtuvo un grado de correlación positiva moderada en las dimensiones condiciones laborales $(\mathrm{r}=0,473 ; \mathrm{p}=0,000)$ e involucramiento personal $(\mathrm{r}=0,434 ; \mathrm{p}=$ 0,000); y correlación positiva baja en las dimensiones comunicación $(r=0,344 ; p=0,000)$ y supervisión $(r=0,296 ; p=0,001)$ del clima organizacional. Además, dicha correlación es significativa por tener un $\mathrm{p}-$ valor $<0,05$.

\section{Hipótesis estadística}

Ho: No existe relación significativa entre el clima organizacional y la satisfacción laboral de los colaboradores del área asistencial del Hospital II-E Banda de Shilcayo, 2018. 
$\mathbf{H}_{\mathrm{i}}$ : Existe relación significativa entre el clima organizacional y la satisfacción laboral de los colaboradores del área asistencial del hospital II-E Banda de Shilcayo, 2018.

\section{Tabla 5}

Resultados de la correlación entre las variables clima organizacional y satisfacción laboral.

\begin{tabular}{|c|c|c|c|}
\hline & Correlaciones & $\begin{array}{c}\text { Clima } \\
\text { organizacional }\end{array}$ & $\begin{array}{c}\text { Satisfacción } \\
\text { laboral }\end{array}$ \\
\hline \multirow{3}{*}{$\begin{array}{l}\text { Clima } \\
\text { organizacional }\end{array}$} & Correlación de Pearson & 1 &, $460 * *$ \\
\hline & Sig. (bilateral) & &, 000 \\
\hline & $\mathrm{N}$ & 119 & 119 \\
\hline \multirow{3}{*}{$\begin{array}{l}\text { Satisfacción } \\
\text { laboral }\end{array}$} & Correlación de Pearson & $460 * *$ & 1 \\
\hline & Sig. (bilateral) &, 000 & \\
\hline & $\mathrm{N}$ & 119 & 119 \\
\hline
\end{tabular}

Fuente: Elaboración propia procesados en SPSS $v 25$ respecto a los puntajes totales

$$
\text { obtenidos. }
$$

La tabla 5 se puede observar el coeficiente de correlación de Pearson $(0,460)$ el cual nos precisa que si existe una correlación positiva moderada entre las variables clima organizacional y la variable satisfacción laboral, tanto en la tabla como en la figura lo cual podemos afirmar que si hay una relación lineal fundamentado en la prueba de Pearson, en tanto el coeficiente laboral de los colaboradores administrativos se ve influenciado por el clima organizacional del área asistencial del Hospital II-E Banda de Shilcayo, 2018.

\section{Coeficiente determinante}

$$
\begin{aligned}
& X^{2}=r^{2 * 100} \\
& X^{2}=(0.460)^{2 * 100} \\
& X^{2}=0.2113 * 100 \\
& X^{2}=21 \%
\end{aligned}
$$




\section{Figura 1.}

\section{Correlación entre las variables clima organizacional y la satisfacción laboral}

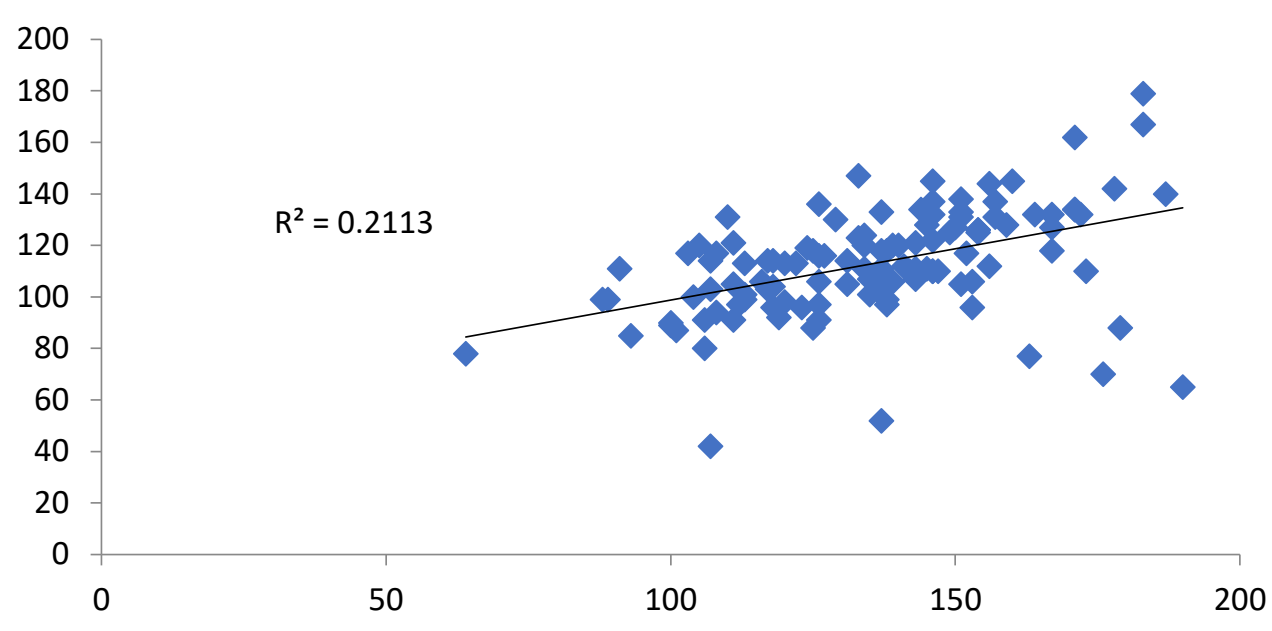

Fuente: base de datos elaborado por el autor: spss ver.24

\section{Tabla 6}

Análisis de varianza entre la variable organizacional y satisfacción laboral

\begin{tabular}{lccccc}
\hline & $\begin{array}{c}\text { Grados de } \\
\text { libertad }\end{array}$ & $\begin{array}{c}\text { Suma de } \\
\text { cuadrados }\end{array}$ & $\begin{array}{c}\text { Promedio de } \\
\text { los cuadrados }\end{array}$ & F & $\begin{array}{c}\text { Valor } \\
\text { crítico de F }\end{array}$ \\
\hline Regresión & 1 & 10882,983 & 10882,983 & 31,337 & 0,000 \\
Residuos & 117 & 40632,984 & 347,290 & & \\
Total & 118 & 51515,966 & & & \\
\hline
\end{tabular}

Fuente: Base de datos elaborado por el autor.

Para poder comprobar si el modelo de correlación de Pearson se ajusta a nuestros datos se observa el valor de Fisher (0,000) que fue ilustrada en la tabla 5, en ese sentido este valor debe ser menos a la posibilidad de cometer al $5 \%(0,05)$, por ello que nuestro valor de Fisher es menor al valor de cometer algún error, es por ello que se concluye que el modelo de correlación de Pearson se ajusta a todos nuestros datos y por lo tanto se acepta que entre el clima organizacional y satisfacción laboral de los colaboradores del área asistencial del Hospital II-E Banda de Shilcayo, 2018.

\subsection{Discusión}

La investigación pretendió fijar una relación entre las variables clima organizacional y satisfacción laboral de los colaboradores del área asistencial del Hospital II-E Banda de 
Shilcayo, entendiendo que cuando las condiciones laborales son favorables y responden a las necesidades y perspectivas de los trabajadores para su desarrollo, ello contribuye a perfeccionar las condiciones de la organización elevando la productividad y efectividad con mejores indicadores sanitarios. Producto del estudio se obtuvo según escala valorativa en relación al clima organizacional y sus dimensiones, que en su mayoría $(41,2 \%)$ los colaboradores refirieron que el clima organizacional según realización personal es desfavorable, sin embargo, en las dimensiones como involucramiento personal, la supervisión, la comunicación, y las condiciones laborales el clima organizacional es medio. Sin embargo, al analizar globalmente el clima organizacional que perciben los colaboradores asistenciales del Hospital II-E Banda de Shilcayo, se evidencia que el 50,4\% se ubica en clima organizacional "media" y el 37,0\% lo califica como "desfavorable". Lo cual refleja que los trabajadores perciben que el clima organizacional no es acorde y tiene una tendencia negativa en el Hospital Banda de Shilcayo.

Resultados que no se relacionan con Carballo-Chiñas (2015), quien encontró en su estudio que el $76 \%$ de los trabajadores del estudio dijeron que si existe un clima organizacional favorable. También se relaciona con Agudelo (2015), quien encontró un nivel medio de clima organizacional. A su vez se relaciona con Carvajal (2014), quien encontró según dimensiones apoyo del jefe, confort físico y cohesión entre colegas como un clima estable sin embargo la dimensión recompensa fue bajo. A su vez se relaciona con Navarro (2017) quien encontró que el 55.9\% sobre clima organizacional es medio favorable, pero con una tendencia a un nivel alto, condición que difiere de lo encontrado en el presente estudio. Igualmente se relaciona con Arévalo (2016) quien encontró un clima organizacional favorable con 50\% seguido del $41.7 \%$ medianamente favorable. También se relaciona con Rivera (2015). Además, se relaciona con Huamán (2015) quien encontró que los trabajadores indicaron tener un clima organizacional regular. También se relaciona con Panduro J. (2012) quien encontró un clima organizacional como nivel de mayor frecuencia a la objetividad y sobre todo la coherencia en la dirección de las características de acuerdo al nivel alto en una escala jerárquica en referencia a el porvenir de la organización. Por el mencionado el clima organizacional es muy importante en las instituciones de salud, ello permite un trabajo en equipo y articulado que contribuya al desarrollo organizacional por lo tanto demanda ser planificado y contar con los 
documentos de gestión que fortalezcan a cada uno de sus colaboradores, entendemos que a un mayor nivel de clima organizacional que a mayor nivel de clima organizacional mayor será el desarrollo de la productividad de la institución.

En relación a la satisfacción laboral encontramos que los colaboradores asistenciales del Hospital Banda de Shilcayo, según escala valorativa lo califican como "mediana satisfacción laboral" en 49,6\%, seguido del 33,6\% que lo ubica en baja satisfacción laboral. Por lo tanto, podemos establecer que los colaboradores asistenciales del Hospital banda de Shilcayo no están satisfechos con la labor que desarrollan en la institución. Resultados que se relacionan con García-Hernández (2016), quien determino que el nivel de satisfacción laboral en ambas empresas fue algo satisfecho, sin embargo, según dimensiones las satisfacciones intrínsecas están algo satisfechos, mientras que referente a la extrínseca se perciben indiferentes. Así mismo se relaciona con Carballo-Chiñas (2015), quien encontró que el $42 \%$ evidenció una satisfacción laboral parcial a regularmente satisfechos, sin embargo, difiere este último dato por que los resultados del presente estudio establecen baja satisfacción. A su vez se relaciona con Navarro R. (2017) quien encontró que el 44.9\% tiene una apreciación de nivel medio de satisfacción laboral. Igualmente, no se relaciona con Arévalo (2016) quien encontró satisfecho a los trabajadores en $85.4 \%$, seguido del $6.3 \%$ que fue medianamente satisfecho. Además, se relaciona con Huamán (2015) quien encontró que los trabajadores indicaron tener una satisfacción laboral regular.

Podemos analizar de lo mencionado que la satisfacción laboral está ligada al clima organizacional, el colaborador debe sentirse contento de los que hace, entendiendo que ello le contribuirá a su desarrollo personal y profesional con nuevas oportunidades laborales o a alcanzar reconocimientos que recompensen los esfuerzos desarrollados. Al realizar el análisis estadístico de relación de las dos variables de estudio (clima organizacional y satisfacción laboral) dentro de los colaboradores del área asistencia del Hospital II-E Banda de Shilcayo, mediante la prueba de correlación de Pearson con un nivel de confianza de 95\%, además se buscó responder a la hipótesis estadística i) Ho: No hay evidencia que exista relación significativa entre el clima organizacional y la satisfacción laboral de los colaboradores del área asistencial del Hospital II-E Banda de Shilcayo, 2018. ii) Hi: existe relación significativa entre el clima organizacional y la satisfacción laboral de los colaboradores del área asistencial del Hospital II-E Banda de 
Shilcayo, 2018. La cual se obtuvo que el coeficiente de correlación de Pearson $(0,460)$ indica que existe una correlación positiva moderada, además nos indica una asociación lineal por el coeficiente de determinación $(0,2113)$, nos explica que el $21.13 \%$ de la satisfacción laboral de los colaboradores asistenciales se ve influenciando por el clima organizacional, además se determinó si el modelo de correlación de Pearson se ajusta a los datos y se observan el valor critico de Fisher (0.000), con probabilidad de cometer error al 5\% (0.05), por lo que se concluye que el modelo de correlación de Pearson se ajusta a los datos y por consiguiente aceptamos la correlación entre las variables entonces existe relación significativa entre el clima organizacional y la satisfacción laboral Resultado que se relaciona con Carballo-Chiñas (2015), quien concluye que la apreciación del personal operativo sobre el clima organizacional es favorable; sin embargo, la mayor parte del personal reflejo parcial y regular satisfacción laboral, lo que a futuro pudiera generar conflictos en el desarrollo institucional. También se relaciona con Agudelo (2015) quien encontró una relación positiva altamente significativa entre el clima organizacional con la dimensión relaciones interpersonales, es decir que falta la relación amistosa y efectiva con sus compañeros. Igualmente se relaciona con Vallejos (2017) quien encontró que el clima organizacional se relaciona significativamente con la satisfacción laboral, siendo el coeficiente de Spearman de 0.701. A su vez se relaciona con Navarro (2017) quien concluye que de acuerdo al coeficiente de Rho de Spearman existe una correlación estadística significativa de 0,857 entre ambas variables. Igualmente se relaciona con Arévalo (2016) quien encontró que existe una relación directa y significativa entre el clima organizacional y satisfacción laboral Pearson= 0,574 valor $\mathrm{p}<0.001$. También se relaciona con Rivera (2015) quien concluye que existe asociación y por tanto influencia del clima organizacional en la satisfacción laboral por que encontró condición favorable al clima organizacional y satisfacción laboral. Además, se relaciona con Huamán (2015) quien concluye que el clima organizacional y la satisfacción laboral constituyen en un elemento esencial para el logro de los objetivos humanos y organizacionales.

Por lo encontrado y analizado podemos establecer una relación directa y significativa entre el clima laboral y la satisfacción laboral, es decir que los gerentes de los servicios de salud deben incluir dentro de sus planes de desarrollo institucional las condiciones que permitan fortalecer y generar cambios con mayor producción y compromiso de sus 
trabajadores, que no sientan solo obligación sino compromiso de hacerlo bien por ellos y por la institución a la cual representan.

\section{CONCLUSIONES}

Existe una correlación positiva moderada entre las variables clima organizacional y satisfacción laboral en el coeficiente de correlación de Pearson (0,460), además confirma que existe una asociación lineal fundamento de correlación de Pearson, el coeficiente de determinación $(0,2113)$, nos declara que el $21.13 \%$ de la satisfacción laboral de los colaboradores administrativos se ve influenciado por el clima organizacional. Al verificar si el modelo de correlación de Pearson se ajusta a la realidad se observa el valor critico de Fisher (0.000), es valor menor a la posibilidad de cometer error al 5\% (0.05), la correlación de Pearson se ajusta a los datos, existe relación significativa entre el clima organizacional y la satisfacción laboral de los colaboradores administrativos del área asistencial del Hospital II-E Banda de Shilcayo, 2018.

El clima organizacional que perciben los colaboradores asistenciales del Hospital II-E Banda de Shilcayo, es clima organizacional medio con el 50,4\% y el 37,0\% lo califica como “desfavorable”. Según dimensiones, el 41,2\% de los colaboradores refieren que el clima organizacional según realización personal es desfavorable; el 45,4\%, 47.1\%, 49,6\% y $45.4 \%$ refieren que en la dimensión involucramiento personal, supervisión, comunicación y condiciones laborales del clima organizacional es media respectivamente.

La satisfacción laboral que presenta el colaborador asistencial del Hospital II-E Banda de Shilcayo, según escala valorativa de la variable satisfacción, se evidencia que, el 49,6\% se ubica en "mediana satisfacción laboral" y el 33,6\% lo califica en baja satisfacción laboral.

Existe correlación positiva moderada en las dimensiones del clima organizacional con condiciones laborales $(\mathrm{r}=0,473 ; \mathrm{p}=0,000)$ e involucramiento personal $(\mathrm{r}=0,434 ; \mathrm{p}=$ $0,000)$; y correlación positiva baja en las dimensiones comunicación $(\mathrm{r}=0,344 ; \mathrm{p}=0,000)$ y supervisión $(r=0,296 ; p=0,001)$ del clima organizacional. Además, dicha correlación es significativa por tener un $\mathrm{p}-$ vaor $<0,05$.

\section{REFERENCIAS}

Álvarez, S. (2001). La cultura y el clima organizacional como factores relevantes en la eficacia del instituto de oftalmología. (Tesis doctoral). Universidad Mayor de San 
Marcos. Lima, Perú de http://intranet.uwiener.edu.pe/univwiener/biblioteca/adquisiciones/nuevas_adqui siciones/tesis/TENF0239.pdf

Avalos, F., Molina, J. (2009). Factores relacionados con la satisfacción laboral de enfermería en un hospital médico-quirúrgico; Investigación y Educación en Enfermería. Citado 21 Set 2018. vol. XXVII, núm. 2, pp. 218-225. Recuperado de http://www.redalyc.org/pdf/1052/105213195007.pdf.

Alvarado C. (2014). Relación entre Clima organizacional y cultura de Seguridad del paciente en el personal de Salud del Centro médico Naval. [Tesis Título Profesional]. Universidad Nacional Mayor de San Marcos. P. 38. Lima - Perú.

Arévalo, P., Tapia E. (2016). Clima organizacional y satisfacción laboral en el personal de salud de la liga contra el cáncer. P. 18. Lima Perú. Recuperado de http://intranet.uwiener.edu.pe/univwiener/biblioteca/adquisiciones/nuevas_adqui siciones/tesis/tenf0239.pdf.

Arévalo, P. (2016). En su tesis: Clima organizacional y satisfacción laboral en el personal de salud de la liga contra el cáncer. P. 30. Lima - Perú. Recuperado de http://intranet.uwiener.edu.pe/univwiener/biblioteca/adquisiciones/nuevas_adqui siciones/tesis/TENF0239.pdf

Asociación para el desarrollo empresarial en Apurímac. (2015). Clima organizacional y satisfacción laboral en la asociación para el desarrollo empresarial en Apurímac, Andahuaylas.

Recuperado

de

http://repositorio.unajma.edu.pe/bitstream/handle/123456789/244/Norma_Quisp

e_Tesis_Titulo_2016.pdf?sequence $=1 \&$ isAllowed $=y$

Blum M, Naylor J. (1982). Psicología Industrial: Sus Fundamentos Teóricos y Sociales. México: Trillas.

Brunet, L. (2011). El Clima de Trabajo en las Organizaciones. México: Trillas.

Borhani, F. (2012). Percepción de enfermería de ética clima y la satisfacción laboral, J. Med Ethics HistMed. EE. UU. P. 20. Citado 21 Set. 2018; (5):6. Recuperado de https://www.ncbi.nlm.nih.gov/pmc/articles/PMC3714120/.http://intranet.uwiene r.edu.pe/univwiener/biblioteca/adquisiciones/nuevas_adquisiciones/tesis/TENF0 239.pdf 
Carballo, A., Romeo, H., Ávalos, M. (2015). Clima organizacional y satisfacción laboral en el personal operativo federal del programa caravanas de la salud en tabasco, Hitos de Ciencias Económico Administrativas. Ene. Citado 21 set. 2018; (59): 4352. Recuperado de file:///C:/Users/Administrador/Downloads/1011-3866-1PB\%20(3).pdf.

Carvajal L. (2011). Clima organizacional en los empleados del E.S.E Hospital San Juan de Dios de Floridablanca. P. 18. Santander- Venezuela.

Carrada T. (2002). La cultura organizacional en los sistemas de salud. ¿Por qué estudiar la cultura? Revista Médica del Instituto Mexicano del Seguro Social [Internet]. Consultado 21/9/2018; 1(1).

Cabrera, G. (1996). Apuntes de Cátedra, Comportamiento Organizacional. Universidad Central de Chile. P.27. Chile. Recuperado de http://www2.uel.br/ccb/psicologia/revista/oclima.htm. Citado en: Marco teórico del clima organizacional. Gallup A. (2013). El país con mayor insatisfacción laboral de Latam -Forbes, sección local, 13 octubre 2013. p. 5. México.

Davis, K. y Newstrom, J. (2003). Comportamiento Humano en el Trabajo; $5^{\circ}$ edición. Editorial McGraw-Hill. P27. México.

Edel R. y García A. (2007.p 52). Clima y Compromiso Organizacional. México: electrónica gratuita. Consultada el 10 de octubre de 2014. Texto completo en:http://corladlima.org.pe/2/download/clima\%20y\%20compromiso\%20org anizacional.pdf. Revisado el 17 de octubre 2014. Recuperado de http://repositorio.ucv.edu.pe/bitstream/handle/UCV/8731/Vallejos_PMI.pdf?seq uence $=1 \&$ isAllowed $=\mathrm{y}$

García, L. (2009). Ministerio de Salud. Documento Técnico: Política Nacional de Calidad en Salud. P. 20. Perú. Recuperado de http://bvs.minsa.gob.pe/local/minsa/1997.pdf

García M, Ibarra M, (2009) Diagnóstico de Clima Organizacional del Departamento de Educación de la Universidad de Guanajuato. P. 40. México. Recuperado el 21.09.18

en: http://www.eumed.net/librosgratis/2012a/1158/definicion_clima_organizacional. html.

Recuperado

de 
http://repositorio.ucv.edu.pe/bitstream/handle/UCV/8731/Vallejos_PMI.pdf?seq uence $=1 \&$ isAllowed $=\mathrm{y}$.

García-Hernández, Y. (2016). En su tesis: Satisfacción laboral del personal de Enfermería en dos instituciones de salud públicas: caso Hidalgo, México. P. 9. Recuperado de https://www.uv.mx/iiesca/files/2016/11/04CA201601.pdf.

Goncalves A. (2000). Dimensiones del clima organizacional. Consultado 27/05/2017; 1(1). http://www.geocities.ws/janethqr/liderazgo/130.html

Hellriegel, D. y Slocum, J. (2014). Comportamiento Organizacional 10 Edición. México: Thomson Learning. P. 35. Recuperado de http://repositorio.ucv.edu.pe/bitstream/handle/UCV/8731/Vallejos_PMI.pdf?seq uence $=1 \&$ is Allowed $=\mathrm{y}$

Hannoun G. (2011) Satisfacción Laboral [Tesis Título profesional]. MendozaArgentina.: Universidad nacional de Cuyo; 2011.

Huamán, G. (2015). En su trabajo de investigación: Clima organizacional y satisfacción laboral del personal adscrito al Centro de Salud Ascensión Huancavelica. P. 12. Recuperado de http://repositorio.unh.edu.pe/bitstream/handle/UNH/442/TP\%20\%20UNH.\%20ENF.\%200048.pdf?sequence=1\&isAllowed=y

Hernadez-Sampieri R, Collado-Fernández C, Baptista-Lucio P. Metodología de la Investigación Científica. 6ta ed. México: McGraw Hill.; 2006. 888 p.

Locke E. (1976). The nature and causes of job satisfation. . Handbook of Industrial and Organization Psychology [Internet]. Consultado 21.09.18; 1(1).

Lut ,F. (2008). Comportamiento organizacional. (1 ${ }^{\text {a }}$ ed). México: Editorial Mc Graw HILL. $\quad$ P. $27 . \quad$ Recuperado de http://repositorio.unajma.edu.pe/bitstream/handle/123456789/244/Norma_Quisp e_Tesis_Titulo_2016.pdf?sequence $=1 \&$ isAllowed $=\mathrm{y}$

León A. Clima -organizacional (2000). Antesala del aseguramiento de la calidad. Ingeniería y Desarrollo.redalyc.org. P. 26. Colombia. citado 10 Set 2016; 8:2532. Recuperado de http://www.redalyc.org/articulo.oa?id=85200802.

López U, (2013) Tesis profesional: Clima Organizacional Universidad Tecnológica de Tula Tepeji. P. 28. México. Recuperado 21.09.18 en: http://www.uttt.edu.mx/catalogouniversitario/imagenes/galeria/131a.pdf. Recuperado de 
http://repositorio.ucv.edu.pe/bitstream/handle/UCV/8731/Vallejos_PMI.pdf?seq uence $=1 \&$ is Allowed $=\mathrm{y}$

Lozano, A., Santos, M, Arcubia J. (2008). Como influye del clima laboral en la satisfacción del trabajo. Recuperado de http://www.academia.edu/24337940/COMO_INFLUYE_DEL_CLIMA_LABO RAL_EN_LA_SATISFACCI\%C3\%93N_DEL_TRABAJO.

Lut, F. (2008). Comportamiento organizacional. (1ª ed). México: Editorial Mc Graw HILL. $\quad$ P. $27 . \quad$ Recuperado de http://repositorio.unajma.edu.pe/bitstream/handle/123456789/244/Norma_Quisp e_Tesis_Titulo_2016.pdf?sequence=1\&isAllowed=y

Márquez G. (2001). Servicios y Desarrollo. El Caso Venezolano. Consultado 21.09.18; 4:[83-116 pp.].

Meneses, C. (2014). Cultura y clima organizacional. El clima organizacional. Que es y cómo analizarlo. P. 39. Consultado 27/05/2017; 1(1). https://www.amazon.com.mx/s?i=stripbooks\&rh=p_27\%3ACarlos+Alberto+Me neses+Gon\%C3\%A7alves\&ref=dp_byline_sr_book_1

Ministerio de Salud. (2015). Gobierno de Perú, citado 21 Set 2018; Recuperado de http://www.minsa.gob.pe/dgsp/clima/archivos/metodologia_clima.pdf

Ministerio de Salud (2009). Documento técnico: Metodología para el estudio del clima organizacional. In: personas DGdSdl, editor. OMS. Lima-Perú.

Ministerio de Salud (2009). Documento técnico: Metodología para el estudio del clima organizacional. In: personas DGdSdl, editor. Lima-Perú: OMS; 2009. P. 20.

MINSA. (2009). Metodología para el estudio del clima organizacional. Lima-Perú: J.W.G. Servicios Gráficos E.I.R.L. P. 22. Recuperado de http://www.minsa.gob.pe/DGSP/clima/archivos/metodologia_clima.pdf.

Revisado 21.09.18 en: http://repositorio.ucv.edu.pe/bitstream/handle/UCV/8731/Vallejos_PMI.pdf?seq uence $=1 \&$ isAllowed $=\mathrm{y}$

Marín, M., Melgar, A., Castaño, C. (2000). Teoría y Técnicas de Desarrollo Organizacional. Organización Panamericana de la Salud. Guatemala citado 21 Set 2018. Volumen 2. P. 15. Recuperado de 
http://iris.paho.org/xmlui/bitstream/handle/123456789/10059/PSDCG-

T10_v2.pdf? sequence=1\&isAllowed=y.

Monteza, N. (2010). Influencia del clima laboral en la satisfacción de las enfermeras en un centro quirúrgico hospital es-salud-Chiclayo (tesis doctoral) Chiclayo Perú: Universidad católica Toribio de Mogrovejo escuela de postgrado; 2010. Recuperado de http://intranet.uwiener.edu.pe/univwiener/biblioteca/adquisiciones/nuevas_adqui siciones/tesis/TENF0239.pdf

Navarro, R. (2017). En su tesis: Clima organizacional y satisfacción laboral de los trabajadores del Hospital Nacional San Bartolomé. P. 31. Perú. Recuperado de http://repositorio.ucv.edu.pe/bitstream/handle/UCV/6710/Navarro_SRE.pdf?seq uence $=1 \&$ isAllowed $=\mathrm{y}$

Noboa A. (2007). Especificidades del clima organizacional en las instituciones de salud. Cita 21/09/2018; 1(1).

Panduro J. En su tesis: Clima organizacional y la calidad de atención en los Servicios de Salud del Hospital Rural de Picota. P. 10. Periodo junio 2011-mayo 2012.

Picoy D. (2014). Clima organizacional en establecimientos de salud de la Micro Red Villa. $\quad$ P. $25 . \quad$ Disponible en; aulavirtual1.urp.edu.pe/ojs/index.php/RFMH/article/view/335.

Proyecto Salud y Nutrición Básica. (1996). Manual de relaciones interpersonales. P. 1.

Ortiz, P., Cruz, L. (2008). Estudio sobre clima y satisfacción laboral en una empresa comercializadora. P. 13. México. Recuperado de http://pepsic.bvsalud.org/scielo.php?script=sci_arttext\&pid=S1870$350 X 2008000200017$.

Pintado, E. (2011). Gerenciación y Liderazgo conductivo del talento humano. Lima, Perú: Arco Iris S.R.L. Recuperado de http://repositorio.unajma.edu.pe/bitstream/handle/123456789/244/Norma_Quisp e_Tesis_Titulo_2016.pdf?sequence=1\&isAllowed=y.

Randstad W. (2015). La satisfacción laboral de los profesionales españoles aumenta durante dos trimestres consecutivos, Randstad, 7 Abr., sec. Local.

Rivera, I. (2015). En su tesis: Influencia del clima organizacional en la satisfacción laboral del personal asistencial del Centro Quirúrgico, en el Hospital "Félix 
Mayorca Soto" de Tarma. P. 9. Recuperado de cybertesis.unmsm.edu.pe/bitstream/handle/cybertesis/5287/River_ri.pdf?sequenc e.

Robbins, S. (2004). “Comportamiento Organizacional. Conceptos, Controversiales y Aplicaciones". (México: Prentice-Hall Hispanoamérica, 1987, p. 439). Recuperado de http:// www.researchgate.net/publication/40937082_El_ Comportamiento_organizacional_conceptos_controversias_y_aplicaciones. México, 2004.

Taguiri R. (1968). The concept of organizational climate: Exploration of a concept. Rev Taguiri y G H Litwin (dirs) [Internet]. 1968 consultado 17/06/2017; 1(1).

Urbina-Laza O. (2005), Identificación de competencias en el profesional de Enfermería del servicio de Neonatología. Consultado 21.09.18; 1(1). Available from: (http://www.scielo.sld.cu/pdf/ems/v19n2/ems05205.PDF.

Vallejos, M. (2017). En su tesis: Clima organizacional y satisfacción laboral en la Micro red de Salud San Martin de Porres. P. 28. Lima Perú.

Werther W. (2000). Administración de personal y recursos humanos. 5ta ed. Editorial Mc. Graw Hill Interamericana, editor. México: Mc. Graw Hill Interamericana. P. 18. Consultado 21.09.18. 